\title{
Lightning medicine in rural practice
}

With reference to the article by Bhargava AN, Kasundra GM, Khichar S and Bhushan BSK entitled 'Lightning strike induced brachial plexopathy' ${ }^{[1]}$

I think the Journal of Neurosciences in Rural Practice is a perfect vehicle to discuss the pathology of trauma of lightning (keraunopathology) as most lightning strike incidents tend to occur in rural areas. ${ }^{[2]}$ Furthermore, most of the chief injuries tend to be neurological in nature. ${ }^{[3]}$

Lightning medicine (keraunomedicine) is a relatively new and emerging field. Lightning is a multi-physics complex phenomenon having a multiplicity of components such as a thermodynamic component, an electrical component, a magnetic component and even a barotrauma component. ${ }^{[4]}$ Hence the predicted pathology of trauma from a lightning strike incident may be very peculiar indeed!

Unusual skin lesions such as Lichtenburg figures, ruptured eardrums, fractured bones, shrapnel injuries on the skin and even pneumomediastinum have been described in the literature. ${ }^{[5-9]}$

Key points to remember in rural practice when investigating lightning incidents is to try and get as much data as possible. Visit the scene if possible. Consult experts from other disciplines (such as electrical engineers) and try to obtain as much collateral information as possible. Even try and confirm the precise time and pinpoint location of the 'culprit' lightning strike with your local weather service (yes, this is possible!)

Once all the data has been collated, a clear picture of the lightning incident will emerge. The mechanism of lightning injury may then be ascertained. Six injury mechanisms

\begin{tabular}{|l|l|}
\hline \multicolumn{2}{|c|}{ Access this article online } \\
\hline Quick Response Code: & Website: \\
\hline & www.ruralneuropractice.com \\
\cline { 2 - 3 } & \\
\hline & DOI: \\
\hline
\end{tabular}

have been described to date. ${ }^{[10]}$ Understanding the mechanism of injury of lightning strike is essential to understanding the pathology of trauma sustained by the victim.

In conclusion, aforementioned will not only make your day-to-day clinical practice more enriching, but it will add value to your patients' understanding of their injuries and possibly even their treatment regimes.

Ryan Blumenthal
Department of Forensic Medicine, University of Pretoria,
Pretoria, South Africa
Address for correspondence:
Dr. Ryan Blumenthal,
Department of Forensic Medicine, University of Pretoria,
Pretoria, South Africa.
E-mail: ryan.blumenthal@up.ac.za

\section{References}

1. Bhargava AN, Kasundra GM, Khichar S, Bhushan BS. Lightning strike induced brachial plexopathy. J Neurosci Rural Pract 2014;4:399-400.

2. Holle, Ronald L., Raúl E. López, Bradley C. Navarro. Deaths, injuries, and damages from lightning in the United States in the 1890s in comparison with the 1990s. J Appl Meteor 2005; 44:1563-73.

3. Auerbach PS. Wilderness Medicine. $6^{\text {th }}$ ed. Elsevier Mosby. 1600 John F Kennedy Blvd. Ste 1800. Philadelphia, PA 19103-2899. First published 1983. ISBN: 978-1-4377-1678-8. Chapter 3: Lightning Injuries. Philadelphia, PA: 19103-2899. 2012. p. 60-101.

4. Rakov VA, Uman MA. Lightning. Physics and Effects. Cambridge: Cambridge University Press; 2003. p. 378.

5. Resnik BI, Wetli CV. Lichtenberg figures. Am J Forensic Med Pathol 1996;17:99-102.

6. Redleaf MI, McCabe BF. Lightning injury of the tympanic membrane. Ann Otol Rhinol Laryngol 1993;102:867-9.

7. Kannan RY, Chester DL, Titley OG. Combined bennet's fracture subluxation and scapho-Trapezio-trapezoidal dislocation secondary to lightning strike. J Trauma 2004;57:1351-3.

8. Blumenthal R. Secondary missile injury from lightning strike. Am J Forensic Med Pathol 2012;33:83-5.

9. Halldorsson A, Couch MH. Pneumomediastinum caused by a lightning strike. J Trauma 2004;57:196-7.

10. Blumenthal R, Jandrell IR, West NJ. Does a sixth mechanism exist to explain lightning injuries? Investigating a possible new injury mechanism to determine the cause of injuries related to close lightning flashes. Am J Forensic Med Pathol 2012;33:222-6.

How to cite this article: Blumenthal R. Lightning medicine in rural practice. J Neurosci Rural Pract 2014;5:325.

Source of Support: Nil. Conflict of Interest: None declared. 